\title{
DUAL ALLOY DISK DEVELOPMENT
}

\author{
D. P. Mourer*, E. Raymond** S. Ganesh*** and J. Hyzak**** \\ *GE Aireraft Engines \\ Lynn, MA \\ **GE Aircraft Engines \\ Evendale, Oh. \\ *** GE Power Systems \\ Schenectedy, NY \\ *****Wyman Gordon \\ Worcester, Ma.
}

\section{Abstract}

A high integrity dual alloy disk (DAD) process was demonstrated under Navy contract funding (N00140-89-C-WC14). The forge enhanced bonding (FEB) joining process utilized for DAD manufacture demonstrated metallurgically clean bonds during scale up from test specimens through full scale disks. Use of advanced development alloys KM4 and SR3 for the dual alloy disk yielded mechanical properties meeting the program goals. Tensile strengths in excess of $1378 \mathrm{Mpa}(200$ $\mathrm{Ksi}$ ) were achieved at $649^{\circ} \mathrm{C}\left(1200^{\circ} \mathrm{F}\right)$ with creep capability demonstrated at up to $760^{\circ} \mathrm{C}\left(1400^{\circ} \mathrm{F}\right)$. Mechanical testing across the FEB joint resulted in failures in base metal(not the joint) with strengths/lives equivalent to base metal properties, confirming joint integrity.

Extensive use of finite element modeling of the FEB joining process and the subsequent heat treatment processes proved invaluable in shortening the development cycle as well as minimizing the overall technical risk. The modeling activity enabled definition of a preferred FEB joint configuration enhancing bondline material expulsion--critical for consistent joint integrity. The modeling also alded in defining an aggressive quench from solution heat treat to achieve mechanical property goals while avoiding quench related thermal cracking.

\section{Technical Overview}

A major challenge for any rotor system is to meet the overall goals of conflicting bore and rim mechanical property requirements. The bore requirements are driven strongly by tensile and lower temperature LCF requirements. The rim, however, requires creep and high temperature crack growth characteristics to meet the demands of this region of the disk. As rim temperatures increase, these demands become increasingly difficult to reconcile and challenge the metallurgist for a creative solution. A dual alloy approach is one that uniquely allows the bore and rim composition and microstructure to be tailored to meet the design requirements. GEAE's dual alloy disk process ${ }^{1}$ was further developed and demonstrated on Navy contract funding (N00140-89-C-WC14) ${ }^{2}$ as a means to meet the demands of advanced disk requirements.

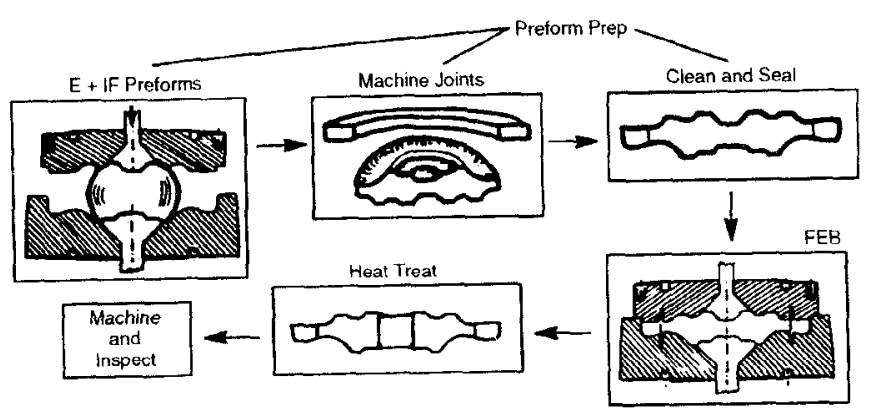

Figure 1. Process schematic of dual alloy disk manutacture via forge enhanced bonding. A high integrity bond is assured by expelling joint material outside the component envelope.
The potential payoff for a $\mathrm{DAD}$ has led to a number of prior studies over the years. A variety of approaches have been auempted and carried to varying levels of demonstration. Methods demonstrating at least partial success include HIP bonding 3,4,5,6 coextrusion and isothermal forging 7,8 and inertia welding 9 . Prior work was carefully reviewed during an cxhaustive downselect to a final preferred method for DAD manufacture. A number of factors were utilized to rank candidate processes. Critical requirements included bond propenies equal or greater to the weaker or the alloy pair, an inherently high integrity interface and a precisely controllable interface location.

The FEB process was selected as preferred by GEAE primarily for its inherent high joint integrity. This high integrity which is required in rotor quality material is insured by the high degree mechanical work at the joint and bondline material expulsion- both key factors in joint integrity. Additionally the FEB process is compatible with existing production facilities, has an inherently precise joint location, and is compatible with the planned supersolvus heat treatment approach.

A typical high pressure turbine disk (HPTD) shape was chosen as the full scale demonstration part configuration. The overall process selected involved assembling the bore and rim forging preforms together followed by FEB of the preforms to physically join the preforms and yield a high integrity joint. This step was followed by annealing the dual alloy configuration above the gamma prime solvus (supersolvus) prior to aging to obtain optimum mechanical properties. An overall process schematic is shown in Figure 1.

The results of earlier work had selected KM4 and SR3, two advanced high strength superalloys 10 as the bore and rim alloys respectively. Compositions are shown in Table I.

\begin{tabular}{|l|c|c|}
\hline Element (w/o) & KMM & SR3 \\
\hline Nickel & Balance & Balance \\
\hline Cobalt & 18 & 12 \\
\hline Chromium & 12 & 13 \\
\hline Molybdenum & 4 & 5.1 \\
\hline Aluminum & 4 & 26 \\
\hline Titanium & 4 & 4.9 \\
\hline Niobium & 2 & 1.6 \\
\hline Carbon & .030 & .030 \\
\hline Zirconium & .030 & .030 \\
\hline Boron & .030 & .015 \\
\hline Hainium & 0 & 0.2 \\
\hline \% Gamma prime & $54 \%$ & $49 \%$ \\
\hline
\end{tabular}

Table I. Nominal chemistries of alloys KM4 and SR3. These alloys were chosen as the baseline alloys for dual alloy disk manufacture.

The extensive use of finite element modeling (FEM) to model the FEB and heat treat processes reduced the cost and time to develop the optimum process combination for subscale and full scale forgings as is discussed in the following sections. 


\section{EEB Process Modeling}

The first area of modeling was the actual FEB process. It has been shown in the past that nickel base alloys similar to those in this study can exhibit abnormal or non homogeneous grain growth during supersolvus heat treatment 11 and this has been related to non superplastic deformation during isothermal forging. Since the intent was to supersolvus anneal the dual alloy disk, it was critical to determine the temperature/strain rate conditions that would render the alloys superplastic during both isothermal forging and the subsequent FEB operation.

As input to the FEM model of this process the specific heat, thermal conductivity, diffusivity, and coefficient of thermal expansion values were determined for each alloy as a function of temperature. In general these properties showed only a small variation between the alloys of this program. To define local strain rates required for superplasticity, flow stress specimens were used to establish the degree of superplasticity as a function of strain rate and temperature. The resultant flow stress data obtained in the range of 1093 to $1038^{\circ} \mathrm{C}\left(2000\right.$ to $\left.1500^{\circ} \mathrm{F}\right)$ was used to establish target strain rates at or below about $0.01 / \mathrm{second}$ or $0.6 /$ minute.

The alloy deformation behavior was used along with forging input data to develop local strain rate histories for the subscale and full scale FEB operations. The forging input data included forging ram strain rate, friction between the die and work piece, and heat transfer between the die and work piece. A typical FEM output is shown in Figure 2. Although the basic ram strain rate is 0.1 /minute or $0.0017 /$ second, the local strain rates in the FEB cavity can reach much higher strain rates, in this case up to $0.04 / \mathrm{second}$. This information was used in a comparative manner by relating the resultant structures of the subscale plane strain forgings to the full scale HPTD and in absolute terms relative to the data from the flow stress specimens. In both cases FEB operations on subscale coupons performed in the right strain rate range yielded sound joints free of critical grain growth.

ALPID 12 was also used to examine the sixteen different cavity geometry's in a design of experiments study to establish correlation's and limitations between cavity parameters and FEB efficiency (as measured by the percent bond line removed per unit volume of metal expelled, and the forging loads for die fill). Forging loads and die stresses were part of the ALPID output, and draft angles to ensure part removal were based on prior experience. Prior FEM analysis indicated the symmetric die cavity design to be most efficient in terms of percent bond line removed per unit volume of metal expelled into the die cavity. As a result the study was based on a symmetric FEB cavity design.

A step-wise regression analysis was performed to establish the significance of correlation's between cavity parameters and percent bond line removed. Additionally, the effect of cavity geometry on forging load, die stresses, and part removal from the die was also considered in determining the most effective die cavity geometry. The conclusion was that for a given cavity volume, the most efficient bond line removal was a function of both the cavity width and entrance radius to the cavity and that die stresses and forging loads were compatible with the desired high degree of bondline matcrial expulsion.

FEB process modeling using ALPDD was also carried out on a full scale high pressure turbine disk geometry to study the effect of using bore and rim alloys with different flow stresses on the resultant FEB process. The objective was to evaluate the robustness of the FEB process and determine if FEB could be safely used to bond materials with flow stresses varying $\geq 2.5 \mathrm{X}$, in this case, 6 and $16 \mathrm{ksi}$. The results of the model, whether the high flow stress material was the bore or rim, was that a successful joint could be made. The interface shapes within the sonic envelope of the forging were very similar, and in either case $82 \%$ of the material was expelled into the FEB ribs in one operation. Two FEB operations remove over $95 \%$ of the original bond line. The results of the model and a physical validation using matenals with different flow stresses are shown in Figure 2. Although some of the fine detail of the joint interface was not precisely reproduced, the macro shape and other key factors such as amount of material expulsion- critical to joint integrity were in good agreement. This result coupled with the knowledge that the preferred alloys would have more similar flow stresses than that modeled in this extreme case further added confidence that analytical modeling would reasonably predict full scale FEB behavior. Additionally it indicated that relative flow stress variations would not limit the process.
Results of prior work had examined the effects of preform joint preparation, canning and sealing the assembled preforms and actual FEB cycles on the final bond integrity. These studies were used to select improved preform joining techniques for the program. The effectiveness of the FEB process in bond line cleanup was substantiated by bonding oxidized preforms (not cleaned or canned) in multiple FEB operations.

Test results using plane strain forging showed that even with preoxidized unbonded preforms, the FEB process can achieve excellent clean up and a sound joint. Tests were performed with a symmetric FEB angle and $2 X$ and $3 \mathrm{X}$ FEB operations and the results are shown in Table II.

\begin{tabular}{|c|c|c|c|c|c|c|c|}
\hline $\begin{array}{c}\text { Initial } \\
\text { State }\end{array}$ & $\begin{array}{c}\text { Joint } \\
\text { Angle }\end{array}$ & $\begin{array}{c}\text { No. of } \\
\text { FEB } \\
\text { Steps }\end{array}$ & $\begin{array}{c}\text { UTS } \\
\text { Mpa }\end{array}$ & $\begin{array}{c}\mathbf{0 . 2 \%} \\
\text { YS } \\
\text { Mpa }\end{array}$ & $\begin{array}{c}\text { Elong } \\
\%\end{array}$ & $\begin{array}{c}\text { RA } \\
\%\end{array}$ & $\begin{array}{c}\text { Failure } \\
\text { Location }\end{array}$ \\
\hline $\begin{array}{c}\text { Oxidi- } \\
\text { zed }\end{array}$ & OF & $2 \mathrm{X}$ & 1359 & 1104 & 9.5 & 8.7 & $\begin{array}{c}\text { Bond } \\
\text { Line }\end{array}$ \\
\hline $\begin{array}{c}\text { Oxidi- } \\
\text { zed }\end{array}$ & $0^{\circ} \mathrm{F}$ & $3 \mathrm{X}$ & 1580 & 1111 & 20.7 & 18.6 & $\begin{array}{c}\text { Base } \\
\text { Metal }\end{array}$ \\
\hline $\begin{array}{c}\text { Oxidi- } \\
\text { zed }\end{array}$ & $45^{\circ} \mathrm{F}^{\circ}$ & $2 \mathrm{X}$ & -- & 1152 & 2.5 & 1.0 & $\begin{array}{c}\text { Bond } \\
\text { Line }\end{array}$ \\
\hline
\end{tabular}

Table II. Test results on pre-oxidized FEB coupons. Excellent bonding is demonstrated even with this gross level of intentional bond line contamination.
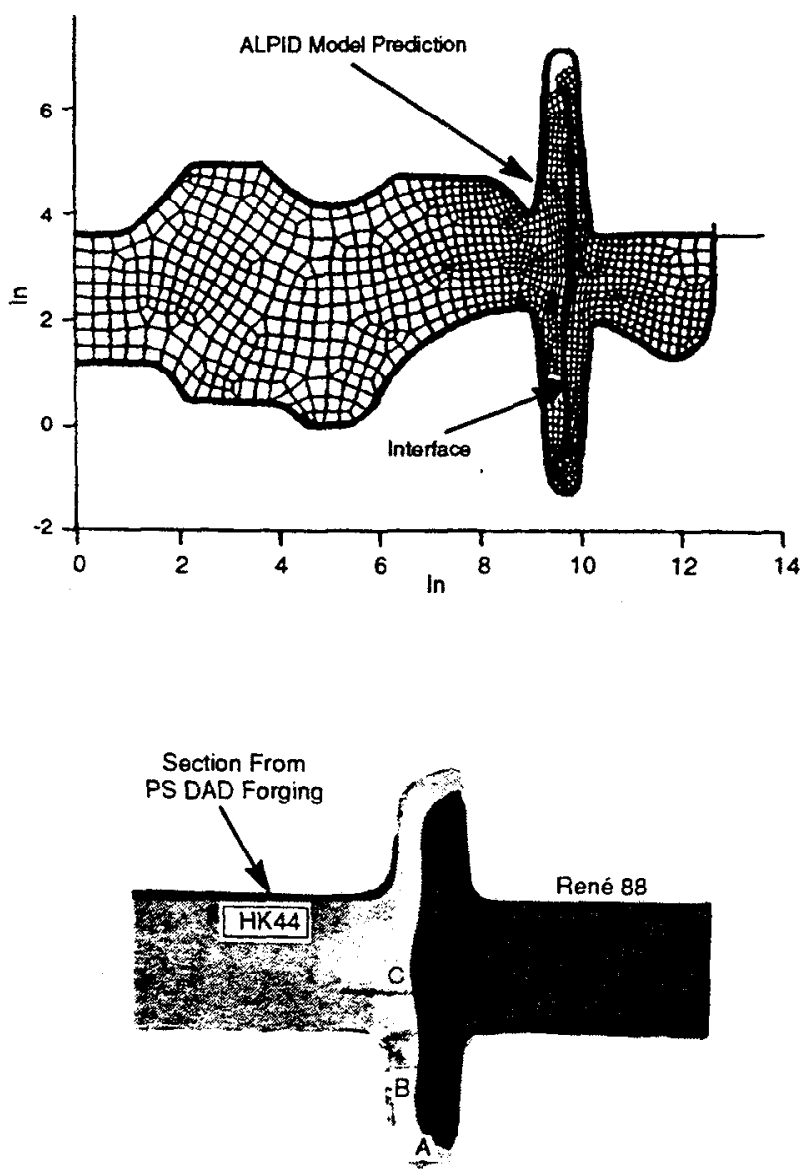

Figure 2. Mathematical model (upper) and physical verification (lower) of FEB material flow. Excellent agreement is demonstrated validating the model fidelity even with $a \geq 2.5 X$ differential in material flow stresses.

The $0^{\circ}$ (vertical) FEB cavity was determined to be an effective joint angle in expelling the material at the original interface. The process 
ends itself to rework or component salvage via use of a $3 X$ FEB versus a $2 X$ FEB or $1 X$ FEB if the interface is severely oxidized. This should not be required in routine production but rework potential is a necessary consideration in any production environment. It was determined that bondline quality can be deduced from the quality of the material expelled into the FEB cavity; if the expelled bondline material is contamination free, the internal joint will be also.

\section{Eull scale EEB Modeling}

The FEB cavity location and dimensions for the full scale forgings were finalized at $24.1 \mathrm{~cm}\left(9.5^{\prime \prime}\right)$ radial location. This selection was based on the subscale modcling results, plane strain and mini disk forging results, and discussions with die design personnel.

To ease part removal from the die after FEB and minimize stress concentration at the cavity root, a decision was made to build segmented dies for the full scale forgings. This required the parting of the die block at the cavity center line and the fitting of a separate die block insert. The value of such design was demonstrated in the mini disk forging trials and in full scale die stress analysis. Modeling indicated that a fully segmented design could cause significant radial displacement and, plastic deformation of the top die punch where it contacts the bottom die along the die wall. Based on the analysis a decision was made to use a partially segmented top die and a fully segmented bottom die. A cross section of the top and bottom dies is shown in Figure 3. Finite element modeling of the $\mathrm{FEB}$ process is illustrated in Figure 4 .

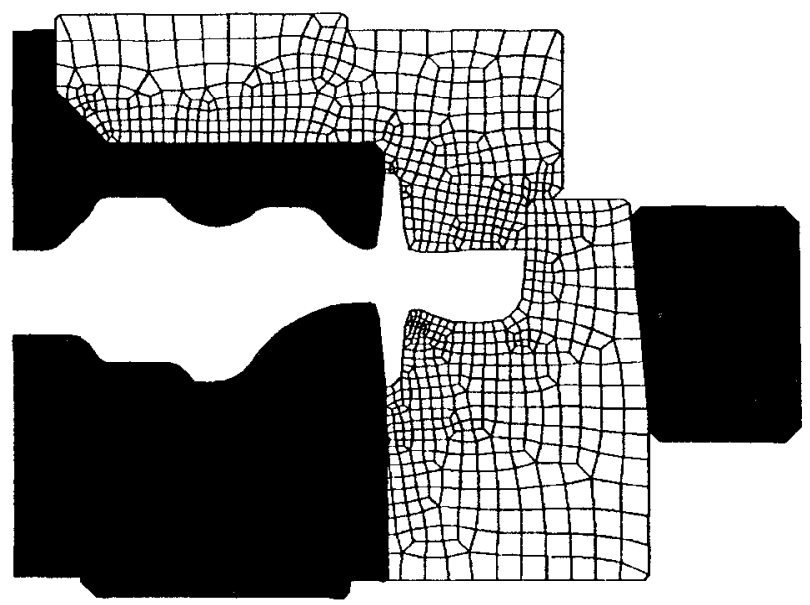

Figure 3. Cross section of the die stack finite element model. This portion of the study was used to verify the acceptability of the preferred segmented die concept.

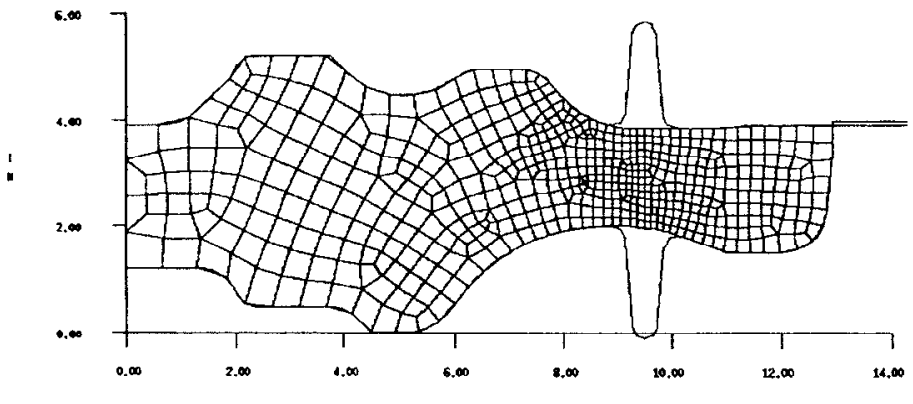

Figure 4. Finite element model results at the start of the FEB operation. This model was used to validate the desired joint flow characteristics.

The pre FEB shape is shown in Figure 4, and the final effective strains in the FEB area are shown in Figure 5. These models compared the predicted deformation of the full scale disk with the subscale mini disk and the plane strain forgings. The results indicated there would be sufficient preform interface removal and residual strain in the bond line to produce a clean bond. The analysis confirmed the subscale coupon study findings that $82 \%$ of the original bond line would be removed in one FEB operation and $95 \%$ would be removed by two FEB operations.

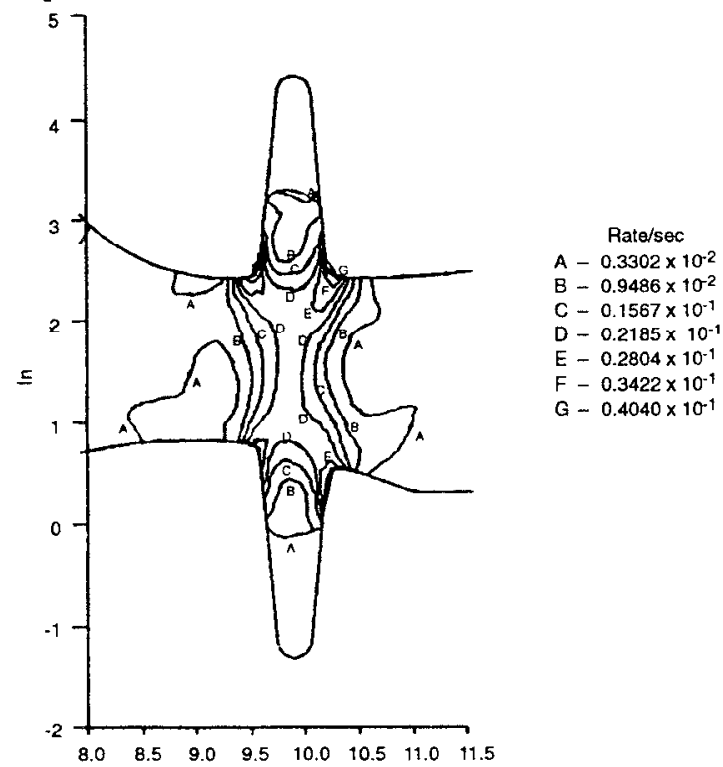

Figure 5. Finite element model results for the FEB operation. The predicted strains were utilized to assure desired material flow in the joint region was achieved

\section{Heat Treat Modeling}

The objective of this phase of the study was to evaluate the feasibility of a standard supersolvus heat treatment to meet bore, rim, and joint property goals without causing quench cracking, excessive residual stress, and/or abnormal grain growth. Hcat transfer and thermal stress FEM modeling was used in conjunction with experimental trials to evaluate the altemate techniques $13,14,15,16$

A focus of FEM HT modeling was the solution annealing quench process. Before thermal modeling in the full scale high pressure turbine disk (HPTD), the NIKE/TOPAZ ${ }^{17,18}$ computer programs from Lawrence Livermore Laboratories were used to model several simpler configurations in order to validate these programs for this application. The stress distributions and deformations in cylinders under the action of internal and extemal pressures, with and without interference, with and without thermal gradients were modeled. The results were in good agreement with the exact closed-form analytical solutions. With the programs thus validated, the full scale thermal modeling was initiated.

As a class these high strength, high gamma prime content alloys typified by SR 3 and KM 4 are prone to thermal stress cracking upon cooling from the supersolvus anneal ${ }^{13}$. This occurs because the thermal stress generated near the surface of a part during cooling due to the extreme thermal gradients exceeds the tensile strength of the alloy at a point when it also has a low ductility. On cooling tensile testing for the two alloys was performed to determine limits for quench rates. This data established the relative strength and ductility at various temperatures as the alloy cools from solution annealing and provided a comparative limit versus quench related stresses predicted by modeling. This approach has been previously described 13

Preliminary studies had indicated that a minimum cooling rate of about $121^{\circ} \mathrm{C}\left(250^{\circ} \mathrm{F} /\right.$ minute was needed for the range of 1093 to $816^{\circ} \mathrm{C}(2000$ to $\left.1500^{\circ} \mathrm{F}\right)$ to meet the strength and creep goals. It was shown that as the cooling rate increases the hold time fatigue crack growth rate of the alloys tcnds to increase, but this varies with alloy. Tensile and creep properties have also been linked to quench rate variations 19 . It was also shown that residual stresses increase with increase in cooling rate, so the cooling rate distribution in the part must be kept in control. 

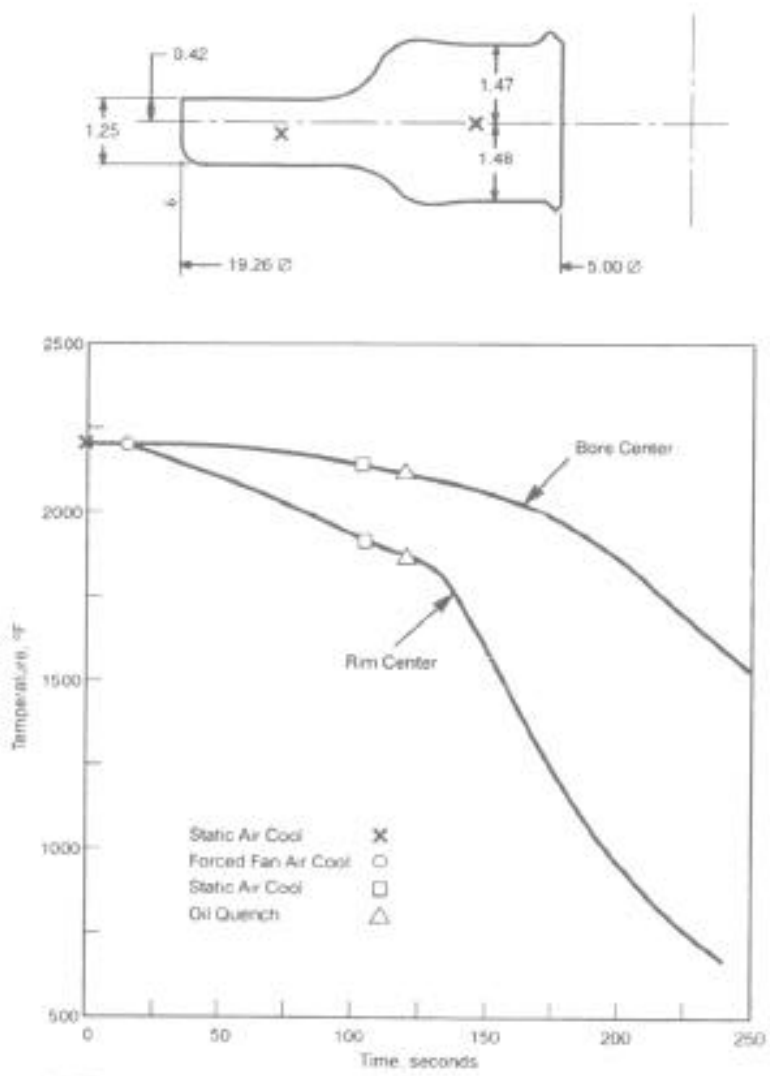

Figure 6. Heat treat trial results simulating the combination static air/fan air/oil quench procedure. This data is representative of the final route chosen for dual alloy disk manufacture.
Preliminary trials were conducted using a thermocoupled high pressure turbine disk of the approximate shape as the full scale dual alloy disk to determine what cooling rates could be expected with normal type qu enchants. One such trial used a cycle of heating the disk wo

$1204^{\circ} \mathrm{C}\left(2200^{\circ} \mathrm{F}\right)$ in a furnace, transferring to a high velocity fan facility in 15 seconds, cooling in the fan for 90 seconds, transferning to an oil quench tank in 15 seconds, and oil quenching to room temperature. The cooling rates at the rim center and bore center were established in particular for the range of 1093 to $816^{\circ} \mathrm{C}\left(2000\right.$ to $\left.1500^{\circ} \mathrm{F}\right)$ as shown in Figure 6. The cooling rates for the bore locations varied from 111$183^{\circ} \mathrm{C}\left(200-330^{\circ} \mathrm{F} /\right)$ minute and the rim values ranged from 111 $444^{\circ} \mathrm{C}\left(200-800^{\circ} \mathrm{F}\right) /$ minute for this particular trial

As noted the cooling rates increased to very high values towards the surface. Although the required nominal $121^{\circ} \mathrm{C}\left(250^{\circ} \mathrm{F} /\right.$ min quench rates could be met a particular concern was the high surface quench rates approaching $427^{\circ} \mathrm{C}\left(800^{\circ} \mathrm{F} / \mathrm{min}\right.$. Heat treat analysis and physical trials established that this quench rate would result in stresses that would exceed the material strength and cause thermal quench cracking. Thus cooling from the supersolvus temperature must be controlled to avoid thermal cracking problems. Prior work suggested that this surface quench rate/high stress condition could be mitigated by camning the part to reduce near surface quench rates. This was verified by both FEM and coupon trials to substantiate selection of the final detailed heat treat parameters. With quench cracking risk minimized the basic heat treat approach taken was similar to that outlined in Figure 6. Also the heat treat fixture designed specifically for the part has supports which were designed to minimize creep of the part at high temperature and eliminate any possibic dead zones where oil might be trapped during the oil quench and provide an slower than desired quench.

The cooling tensile data along with FEM enabled the selection of the cooling rate necessary to satisfy mechanical property requirements while avoiding thermal stress. The effect of solution temperature and time on grain size, and incipient melting was studied taking into consideration that the normal production fumaces are presently capable of a tolerance of $\pm 8^{\circ} \mathrm{C}\left(15^{\circ} \mathrm{F}\right)$. This data along with the on cooling lemperature profiles and the resulting thermal stresses from FEM modeling allowed the design of an air, fan, and oil quench procedure in combination with canning the surface of the part with stainless stecl to obtain desired mechanical properties without thermal cracking the part.

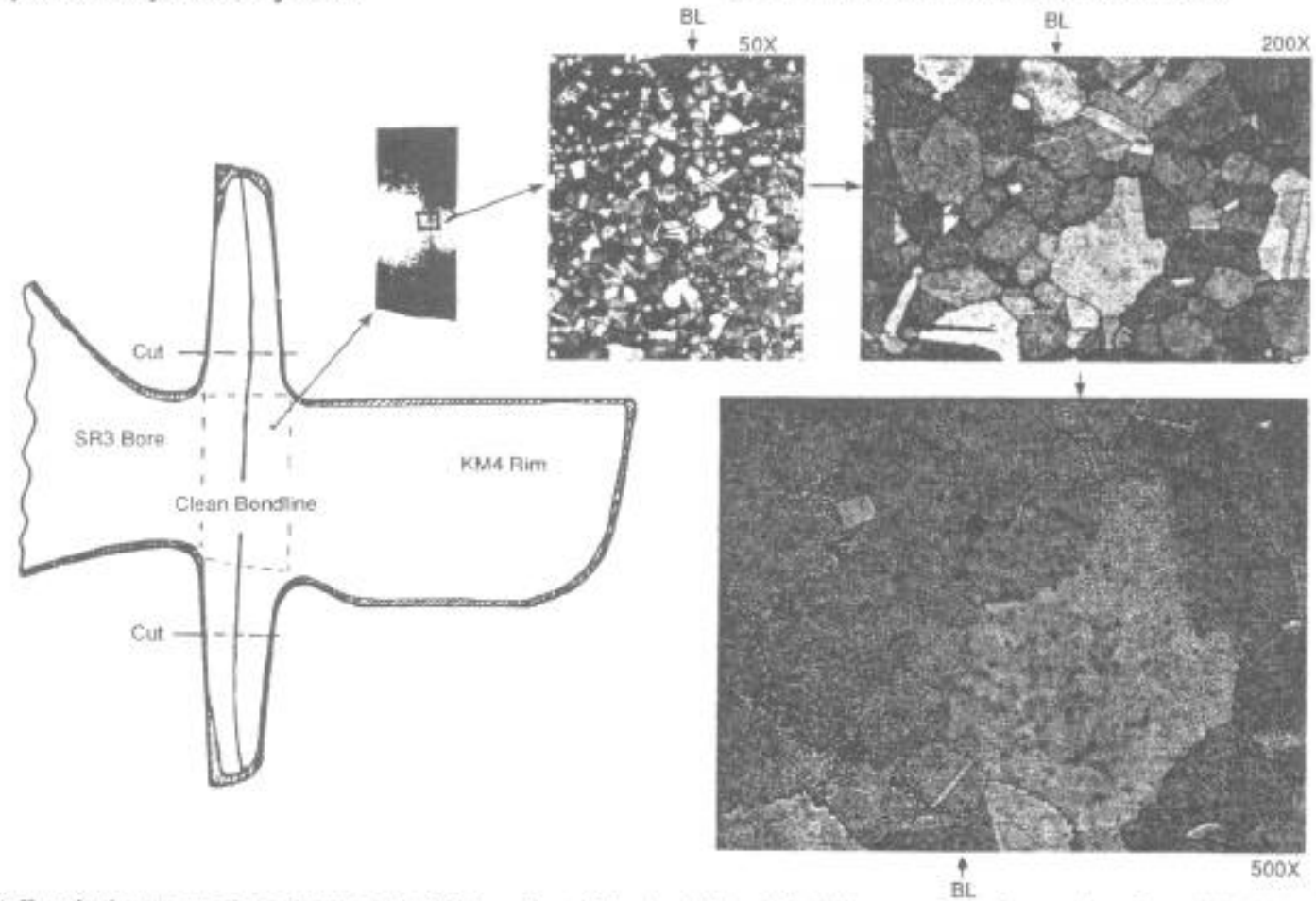

Figure 7. Metallurgical cross sections through the joint region of the dual allog disk. The structures observed confirmed the high degree of integrity or joint cleanliness as predicted by prior madeling. 


\section{Demenstration Disk Manufacture}

The genenal process used by Wyman Gordon in making the full scald disks is illustrated in Figure 1. Bore and rim preforms were isothermally forged. Fabrication of the near net shape can used during the FEB coeration was performed by spinning over a mandrel. Using a template of the dimensions of the preform, the can was dimensionally inspected. After thorough cleaning the rim was lowered on to the bore and the assembly was lowered into the botrom can. The assembly was placed of to a welding tum table and the top can placed on the assembly. First the can was evacuated through the fill stem and then the desired vacuum in the interstice was maintained by crimping the fill twbe. The assembly was then heated and moved into the isothermal press, the joint isothermally forged, and the finished forging ejected from the FEB dies with the knockout

After each of the FEB operations both the top and bottom ribs (or expelled joint material) were sectioned and examined metallographically for joint integrity. Typically this examination was done at the top and base of the rib, and was shown to be a highly sensitive nondestructive measure of bond integrity. For assurance this prototype part was $2 \mathrm{X}$ FEB ed to insure joint integrity. In addition to removing the ribs, preparation for heat treat included machining a four inch diameter center hole into the disk. The disk was recanned with a stainless steel near net shape can followed by a HIP cycle to make the assembly fully integral. The solution anneal was at $1188^{\circ} \mathrm{C}\left(2170^{\circ} \mathrm{F}\right)$ for 2 hours, with a transfer to a high velocity fan and fan cooling. This step was followed by a transfer to an oil quench bath and the forging was oil quenched to room temperature. Several dry runs were made with the equipment and procedures that culminated in successful heat treatment of the final demonstration disk per the intended practice.
After can removal and fluorescent die inspection for surface cracks the disk was then sectioned for full structural inspection and mechanical property determinations. After 2 X FEB both the top and bottom of the top rib was clean as shown in Figure 7. The contour of the bond line in the $2 \mathrm{X}$ FEB ribs are also shown in Figure 7 along with the micro appearance of the bond line near the base of the top and bottom rib. The location from which the sample was taken as well as the structure at $50 \mathrm{X}, 200 \mathrm{X}$, and $500 \mathrm{X}$ is shown. This established that the desired high integrity, defect free joint was obtained. In all cases the bond was clean and acceptable for finish operations and subsequent evaluation.

Figure 7 shows a picture of a macro slice taken from the DAD. The bond line is linear axially oriented, and in the exact radial location predicted. Figure 8 shows a montage of photographs at about $100 \mathrm{X}$ illustrating the grain sizes after heat treatment at various locations in the disk. The grain gizes were all in the desired ASTM 7.9 range. Higher magnification pictures of the structures in the same areas are shown in Figure 8. No arge intragranular gamma prime precipitation is seen indicating that the solution temperature was supersolvus as planned. Figure 8 shows the structures of the grain boundaries in the various locations at higher magnification obtained in the high resolution SEM. Grain boundary precipitates of gamma prime, carbides, and borides can be seen in the boundaries, but not copious amounts. This along with the gamma prime size and shape also shown in Figure 8 indicates that the desired cooling rate was obtained during heat treatment.

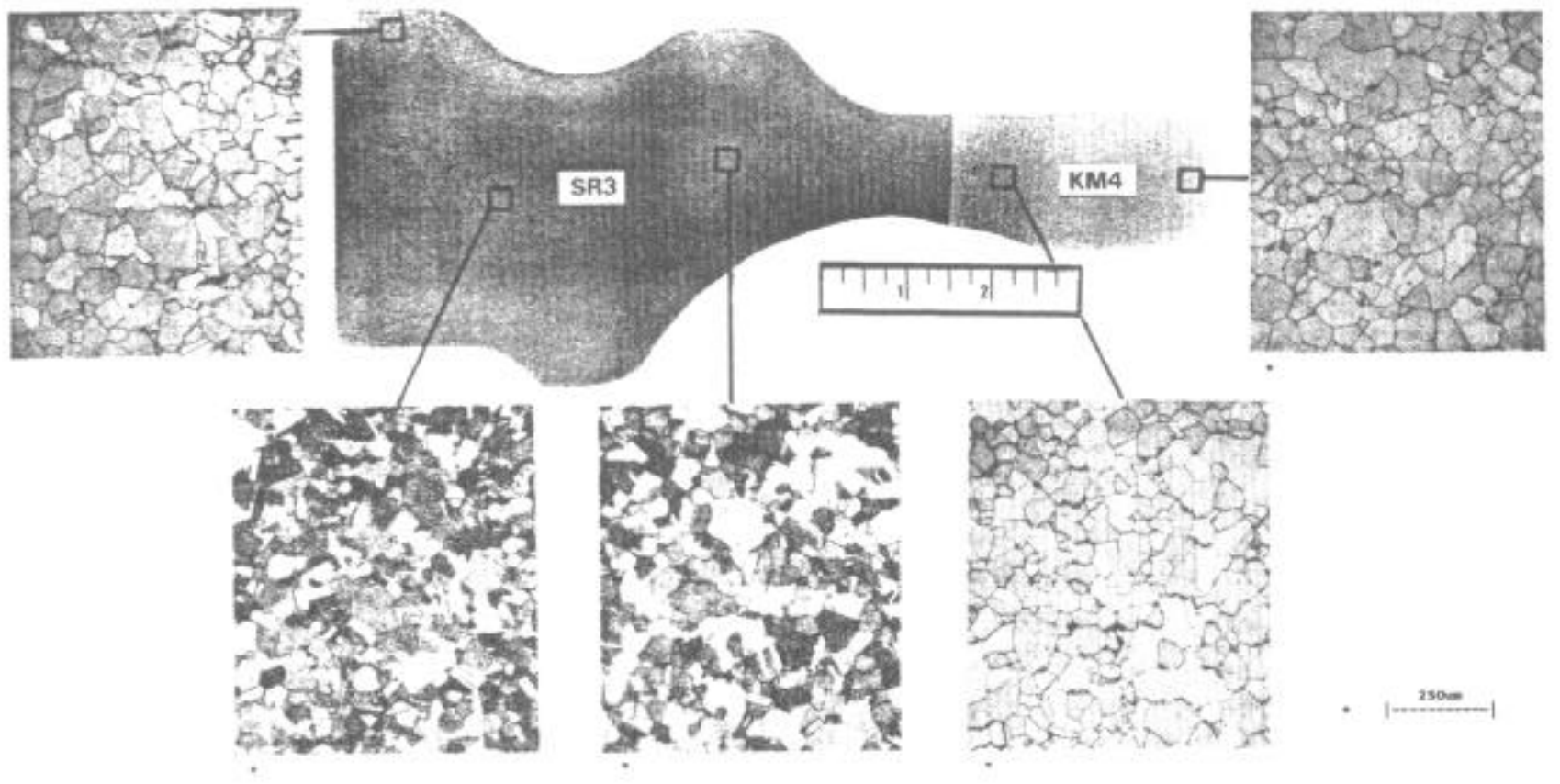

Figure 8. Micrographs illustrating grain size consistency throughout the dual alloy disk forging. These grain sizes met the desired aims. 


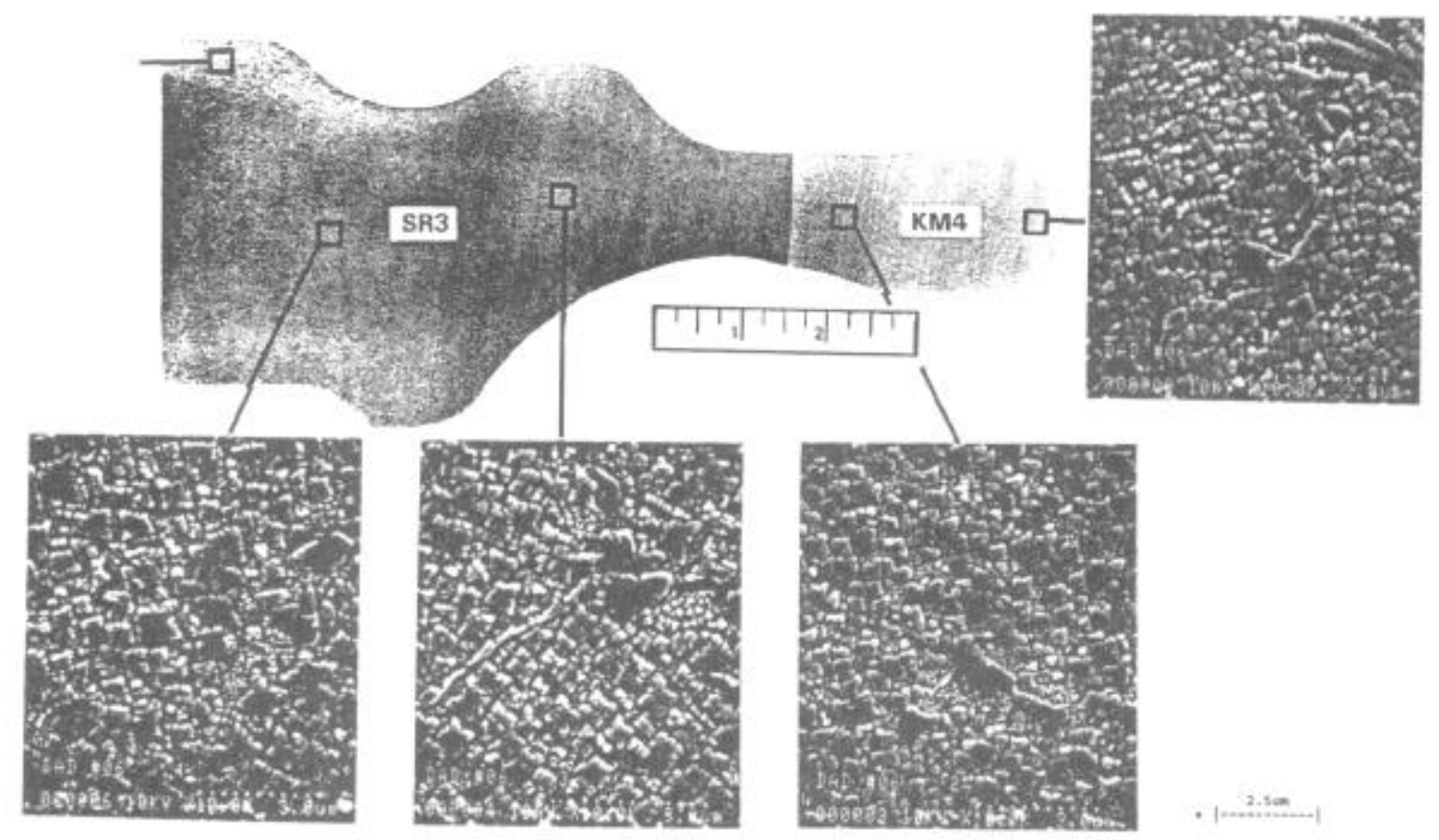

Figure 9. Micrographs illustrating gamma prime size consistency throughout the dual alloy disk forging. These gamma prime sizes confirmed the aim rooling rates hat b

The disk was sectioned for mechanical property determinations. Tests were taken in the bore alloy, rim alloy, and across the joint. Figure 10 shows the tensile results relative to the high temperature goals of the program. Figure 10 shows that the rim alloy and the joint exceeded the tensile goals of the program, but the bore alloy was somewhat below goal.

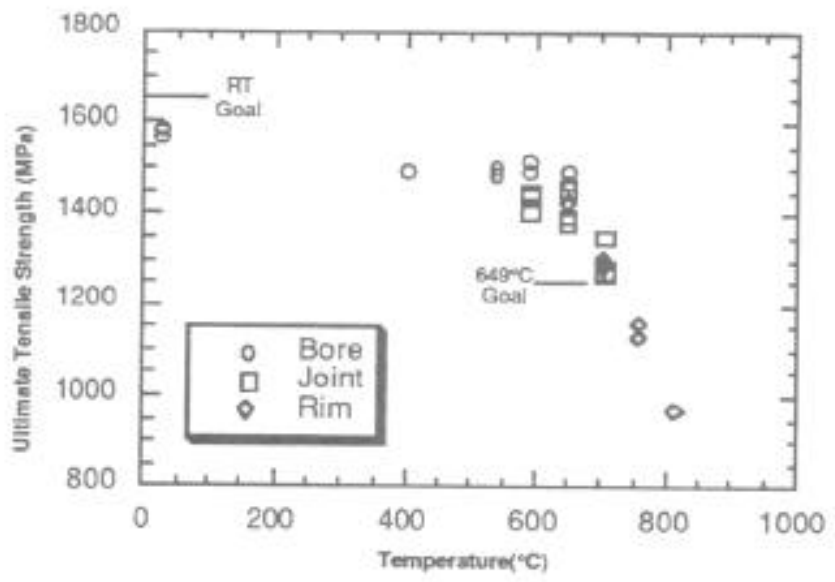

Figure 10. Ultimate tensile strength data for the dual alloy disk. The strength met goals and was similar to single alloy forgings similarly processed. No loss in strength was observed in the joint region.

Similar results were obtained with the $0.2 \%$ yield strength data. Additionally the notch tensile results indicate that all areas are in a notch strengthened condition.

The creep results relative to the goals are shown in Figure 12. Both the bore and rim creep results exceeded the goals of the program. In all cases where joint material was tested, the failure occurred in the base metal with results within the scanter for the bore alloy and the rim alloy.

The analysis of both the structure and mechanical properties of demonstration disk attests to the capability of the FEB process to produce an excellent dual alloy disk.

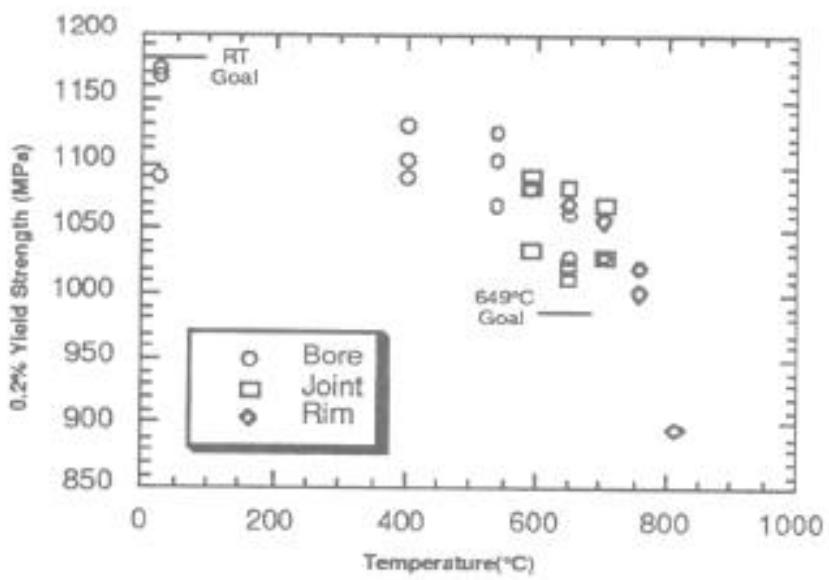

Figure $11.0 .2 \%$ yield strength data for the dual alloy disk. The yield strength met goals and was similar to single alloy forgings similarly processed. No loss in strength was observed in the joint region. 


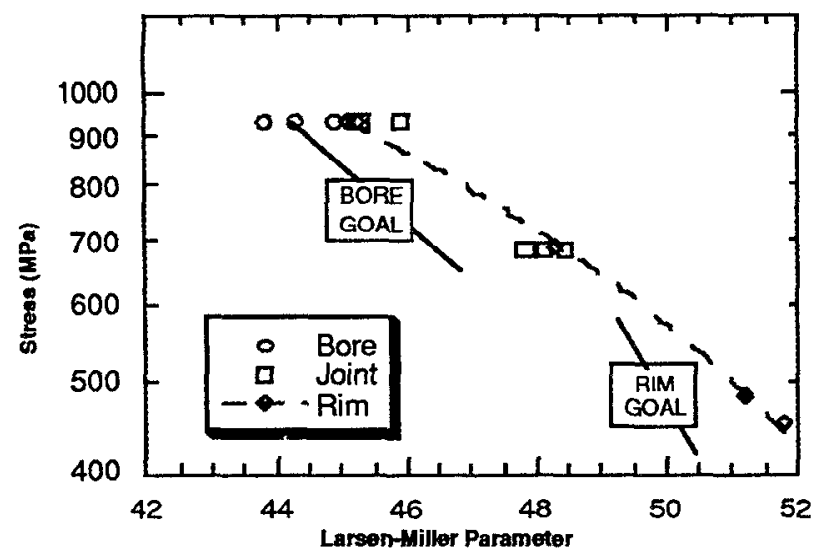

Figure $12.0 .2 \%$ creep data for dual alloy disk. The creep strength met goals and was similar to single alloy forgings similarly processed. No loss in strength was observed in the joint region.

\section{Summary}

A dual alloy disk of SR3 bore-KM4 rim was successfully forged using the FEB process to yield a full scale high integrity dual alloy shape. The established preform preparation process yielded a fully defect free bond line.

The dual alloy disk was successfully heat treated using the baseline treatment developed and incorporation of the canning protection to yield a disk free of thermal stress cracking, and rneeting the structures and mechanical properties expected from SR3 and KM4 heat treated in a similar manner.

The combination of FEM modeling and subscale validation of key processing steps greatly accelerated the development effort and reduced the overall program risk.

\section{Acknowledgments}

This program's success was achieved by the support number of people at both Wyman Gordon and GE Aircraft unfortunately space permits mention of only a few. Ron Tolbert of GEAE is thanked for his tireless support of this effort. Key contributions by Mike Henry of GE Corporate Research were crucial to the success of the program. Modeling support critical to success was provided by Hugh Delgado and Ram Ramikrishnan of Wyman Gordon. Finally the contractual support of the US. Navy and personal support of the Navy DAD program manager, Andrew Culbertson are gratefully acknowledged.

\section{References}

1. J. M. Hyzak et al, U.S.Patent 5,161,950, "Dual Alloy Disk System" April 21, 1992

2. S. Ganesh et al, "Advanced Technology for Turbine Disk Materials (Dual Alloy Disk)," Final Report, September 30, 1994, GE Aircraft Engines, Cincinnati, Ohio. Navy Contract No. N00140-89-C-WC14

3. Weaver, D.M. and Reichman, U.S. Patent 4,063,939, "Composite Turbine Wheel and Process For Making Same"

4 Cross, K.R. U.S. Patent 4,096,615 , "Turbine Rotor Fabrication"

5. Clark, J. et al, U.S. Patent 4,659,288, "Dual Alloy Radial Turbine Rotor with Hub Material Exposed in Saddle Regions of Blade Ring"

6. Ewing, Bruce, "A Solid -To-Solid HIP-Bond Processing Concept For The Manufacture of Dual -Property Turbine Wheels for Small Gas Turbines" in Superalloys 1980 ed. by John K. Tien et al., TMS-AIME, Warrendale, PA, 1980 , pp.169-178
7. Hughes, Anderson and Athey R.L. , "Fabrication and Heat Treatment of a Ni-base Superalloy Integrally Bladed Rotor for Small Gas Turbine Applications" Modem Developments in Powder Metallurey, Volume 14, Special Materials, June 22, 1980.

8. Miller, J.A et al, U.S. Patent 4,479,293 "Process for Fabricating Integrally Bladed Bimetallic Rotors"

9. Stalker, K.W. and Janke, L.P. "inertia Welded Jer Engine Components" ASME paper 71-GT-33, 1971

10. D.D. Krueger, J.F. Wessels, and K.M. Chang, U.S.Patent 5,143,563, "Creep, Stress Rupture and Hold Time Fatigue Resistant Alloys" September 1, 1992

11. J.Y. Guide, J.C., and Y. Honoree, "N18, Powder Metallurgy for Disks, Development and Applications," J. Mat. Eng. and Performance, 2 , 1993, pp. 551 and 556.

12. S.I. Oh, "Finite Element Analysis of Metal Forming Processes with Arbitrarily Shaped Dies" International Journal of Mechanical Science, Vol. 24, 1982, PP 479-493

13. R. A. Walls and P.R. Bhopal, "Property Optimization in Super alloys Through the Uses of Heat Treat Process Modeling" in Superalloys 1988, ed. by S. Reichman et al., TMS-AIME, Warrendale, PA, 1988.

14. T.E. Howsen and H.E. Delgado, "Utilization of Computer Modeling in Superalloy Forging Process Design," in Superalloys 1988, ed. by S. Reictiman et al., TMS-AIME, Warrendale, PA, 1988.

15. J.M. Franchet et al., "Residual Stress Modeling During the Oil Quenching of An Astroloy Turbine Disk," in Superalloys 1992, ed. by S.D. Antolovich et al., TMS-AIME, Warrendale, PA, 1992, pp. 73-82.

16. R.I. Ramikrishnan, "Quench Analysis of Aerospace Components Using FEM," in Proceedings of the First Int. Conf. on Ouenching and Distortion Control, Chicago, 22-25 September 1992, p. 235-242.

17. A. B. Shapiro, "TOPAZ 2D -A Two -Dimensional Finite Deformation, Finite Element Code for Heat Treat Analysis, Electrostatic, and Magenetostatic Problems" (Report No. UCD-20824, July 1986).

18. J.O. Hallquist, "NIKE 2D- A Vectorized, Implicit, Finite Deformation, Finite Element Code for Analyzing the Static and Dynamic Response of 2-D Solids" (Report No. UCID-19677, Rev 1, December 1986).

19. P.R. Bhowal, E.L. Wright, and E.F. Raymond, "Effect of Cooling Rate and $\gamma^{\prime}$ Morphology on Creep and Stress-Rupture Properties of a Powder Metallurgy Superalloy," Met Trans., 21A, pp. 1709-1717. 